\title{
First-class science all over the world
}

$\mathrm{M}$ ost scientists take opportunities to discuss their work with interested colleagues for granted, but developing these resources in places with a small science community requires effort and ingenuity. "Initially I'd invite ten people, and one would show up," says Hossein Esteky of the Institute for Physics and Mathematics School of Cognitive Sciences in Tehran, who has created a respected program in cognitive neuroscience over the last five years. His institute now hosts 12-15 leading scientists a year. Such dedicated investigators have created world-class research programs in developing regions despite limited resources. The scientific community needs to learn from their stories and work toward providing more effective support for such efforts.

Outstanding science requires access to the latest research findings and ideas, making it almost impossible to achieve in isolation. Fortunately, the internet has made international communication much easier. "Being out of the mainstream is really an intellectual state; it's not a physical state. The 'hallway' can be the size of a continent," notes Gregory Quirk of Ponce School of Medicine in Puerto Rico. When travel funding is limited, Quirk uses videotaped seminars from the internet to produce a virtual lecture series. Online access to scientific journals also has improved dramatically over the last decade, with many publishers offering free or reduced-price access for developing countries through programs like the Health InterNetwork Access to Research Initiative.

Staying in touch with outside scientists helps researchers in developing countries to become a valued part of the world community. There are practical benefits as well, including help with visa problems and other government regulations, equipment donation and comments on manuscripts written in a non-native language. Both sides can benefit from scientific collaboration and the exchange of students. If an isolated university has good outside contacts, working in the home country becomes more attractive to faculty who have studied abroad.

Getting to know foreign scientists presents even stronger advantages to students. Beyond exposing them to a variety of high-quality science, such contact assures them that the outside world is interested in their work. "Working in relative isolation, it's even more important for students to get critical feedback on their work from experts in the field," says Shona Chattarji of the National Centre for Biological Sciences in Bangalore. In some cases, leading outside scientists come to know these students well enough to write them letters of recommendation and advise them on career issues.

Relationships with a foreign scientist's laboratory often begin with personal connections, developed at a conference or through an introduction from another scientist. The first visit may be motivated by the opportunity to travel to an unusual part of the world or to interact with enthusiastic students. Also, Quirk explains, "Science is a meritocracy, and people want to see these historical imbalances righted. If someone's out there fighting the windmills, they will try to help." With time, col- laborations tend to become more bilateral. Chattarji notes that "more and more, it's the science" that motivates people to work with his group and visit his laboratory.

Unfortunately, such cultural exchange is a double-edged sword for developing countries. Foreign visitors can help students learn how to apply for graduate school or postdoctoral positions in other countries, but rarely emphasize the possibility of working in their home country. Students who go abroad provide expertise and encouragement to those studying at home, but hearing about the resources available in other countries tempts others to leave. Even for those who want to return home, positions are often difficult to find. Ranulfo Romo of the Universidad Nacional Autonoma de Mexico points out another problem: "When someone returns to Mexico, the community here always thinks that person couldn't get a job abroad." Such attitudes make it difficult to recruit good faculty. Many granting agencies are attempting to reduce this 'brain drain' by offering funding for scientists to return home after their training (see background material).

Scientists who succeed in doing first-rate research under difficult circumstances seem to have some attitudes in common. They are willing to ask for help in overcoming local disadvantages, and do not worry too much about imposing on the more fortunate. However, they expect their laboratory's work to meet the standards for publication in highprofile journals, and they are open to constructive criticism. "The idea that good research can only come from major research institutions is the kind of self-perpetuating notion that keeps expectations low for smaller institutions," explains Quirk. These successful scientists also cultivate local students, who tend to be very highly selected but not well trained when entering the laboratory. To do so, they provide intensive training while setting high standards for performance. This sort of training requires a very strong laboratory culture, which includes a lot of contact with the investigator.

How can scientists improve the odds of success in this uphill battle? A web clearinghouse to match needs and offers of equipment and expertise would be useful, along with more funding for foreign lectures and return-home grants. Encouraging students from developed countries to work overseas would help them to understand the problems, as would inviting foreign scientists to speak at prestigious universities. Developing nations also need to do their part, by reducing bureaucracy, limiting teaching to allow time for research, and selecting and promoting faculty for their abilities rather than their political connections.

For those who establish a productive laboratory in a developing country, the rewards are clear. One person can make a major difference in the lives of students and in a country's scientific development. Chattarji sums it up: "I'm doing five times more than I imagined I could do here."

View background material on Connotea at http://www.connotea.org/user/NatNeurosci/tag/ editorial200603. 